\title{
Bodybuilder Gynecomastia: Etiology, Characteristics, and Management
}

\author{
HELMY ELWAKEEL, M.D.; MOHAMED H. ABOUARAB, M.D. and HASSAN M. KHOLOSY, M.D. \\ The Department of Plastic Surgery, Faculty of Medicine, Alexandria University, Egypt
}

\begin{abstract}
Background: Bodybuilder gynecomastia represent a special entity, being secondary to use/abuse of anabolic steroids leading to glandular enlargement as the sole or the main underlying pathology with an occasional fatty element. Typical management entails complete gland excision through the least visible scar, (typically periareolar) with preservation of pectoral muscle and fascia integrity. Adjuvant small volume liposuction is needed in some cases with a fatty element.
\end{abstract}

Patients and Methods: The study enrolled a series of 13 bodybuilders with gynecomastia and a history of anabolic steroids use/abuse. All cases presented with glandular tissue enlargement, with fatty element noted in 4 cases. Operations were done under general anesthesia with tumescent fluid infiltration. Through an inferior periareolar incision, almost the whole enlarged gland was excised, with adjuvant liposuction as indicated. Meticulous hemostasis and preservation of pectoral fascia integrity aimed to minimize excessive scaring beneath a thin overlying areolar skin flap and possible subsequent adhesions and contour irregularities.

Results: All cases achieved final satisfactory results with high patients satisfaction. Early complications included minor hematoma in one case. Probably this was the cause of later dynamic depression seen with pectoral muscle contraction noted at 6 months follow-up and resolved spontaneously during the next year.

Conclusion: Bodybuilder gynecomastia management entails almost complete glandular tissue excision with limited liposuction in some cases. Meticulous technique including proper hemostasis is important to avoid even the minor contour irregularities and other complications in such demanding cases seeking perfect shape.

Key Words: Bodybuilder gynecomastia - Anabolic steroids - Periareolar incision.

\section{INTRODUCTION}

Excessive male breast enlargement defines gynecomastia; a common problem with various possible etiologies, the most common being idiopathic [1]. The patients suffer a significant psychological upset, a lack of self-esteem, and social embarrassment [2]. Underlying pathology involves fatty deposits and/or glandular tissue hypertrophy. Fat accumulation is the common feature of gynecomastia in the general population with a variable contribution of glandular element $[\mathbf{1 , 3}]$. Liposuction alone or combined with excision of any enlarged glandular tissue by pull thorough technique or open surgical excision (mostly through a periareolar incision) are the mainstay of treatment in mild to moderate cases without significant ptosis [4-9].

Gynecomastia in bodybuilders represents a special entity, being secondary to use/abuse of anabolic steroids leading to glandular enlargement as the sole or the main underlying pathology with little contribution of fat accumulation [10-13]. Cyclic anabolic steroid use would result in suppression of endogenous testosterone. As the supplementary testosterone is stooped, and before normalization of endogenous testosterone output, a severely altered testosterone/estrogen ratio in favor of the latter would repeatedly stimulate glandular tissue growth [13]. Histologic examination of excised glands reveals hypertrophy of both breast parenchyma and duct system [13].

Most bodybuilders gynecomastia present with mild to moderate enlargement without skin redundancy. Liposuction has a limited role in management. Complete gland excision is the key for successful treatment, to avoid recurrence from any residual hormone-sensitive tissue [13].

Although breast element is typically mild to moderate in bodybuilder, yet its management is challenging in many aspects. The cases are more aware of their physique/body shape and more demanding seeking perfection powered by professional competition. Their use/abuse of anabolic steroids and over-the-counter supplements like omega fatty acids increase the bleeding risk and hematoma formation. Moreover, inadequate gland 
excision carries a high risk of recurrence, mostly secondary to the past/continued use of anabolic steroids [12-15]. Complete gland excision through the least visible scar, without injury to the pectoral muscle, is the key to satisfactory results. Adjuvant liposuction may be needed in some cases with fatty elements and/or mild skin redundancy [13].

To have a common base for communication and management of gynecomastia Simon [16] proposed a simple gynecomastia classification into 4 grades:

- I: Mild enlargement without redundant skin.

- IIa: Moderate breast enlargement without redundant skin.

- IIb: Moderate breast enlargement with minor skin redundancy.

- III: Gross enlargement with ptosis mimicking female breast.

The present work represents the author's experience with the management of a small series of bodybuilder gynecomastia. Investigating how frequent the potential role/need for adjuvant liposuction which was variably reported in the literature [12-15] as an adjuvant to the well-reported need for surgical glandular tissue excision in all cases.

Aim:

Reporting unique aspects of bodybuilder gynecomastia presentation and management.

\section{PATIENTS AND METHODS}

During the period between March 2013 to April 2019, 13 cases of bodybuilder gynecomastia aged from 23 to 41 years (mean 31.2 years) were surgically corrected in private practice. 12 cases suffered from mild (Simon grade $\mathrm{I}=5$ cases) to moderate (Simon grade $\mathrm{IIa}=7$ cases) breast enlargement without skin redundancy. One case presented with mild enlargement with mild skin redundancy a situation not specified by Simon's classification. All cases reported past and/or current use of anabolic steroids and over-the-counter supplements.

\section{Before surgery:}

Through medical examination and history, tacking included the duration of gynecomastia, past post-pubertal breast enlargement, and anabolic steroids intake. Routine lab investigations included $\mathrm{CBC}, \mathrm{PT}$, hormonal essay (total and free testosterone levels, Estrogen and Prolactin level), liver and kidney profile. Patients were instructed to stop intake of anabolic steroids, aspirin, and over-the- counter supplements/vitamins especially vitamin $\mathrm{E}$ and fish oils for at least 2 weeks before surgery.

Informed patients' consent included potential complications (hematoma, seroma, nipple vascular compromise, or sensory changes) and the possibility of postoperative asymmetry.

Patients were marked in the upright position, the extent of glandular enlargement was mapped on the skin, any excess subcutaneous fat was also marked for adjuvant liposuction as indicated.

\section{Surgical technique:}

Surgery was performed under general anesthesia supplemented with tumescent local anesthesia for easier dissection.

Tumescent local anesthetic solution $(500 \mathrm{ml}$ saline mixed with $1 / 2 \mathrm{mg}$ adrenaline, $20 \mathrm{ml} 2 \%$ xylocaine, and $5 \mathrm{ml} 8.4 \%$ sodium bicarbonate) was infiltrated into the breast, from the level of pectoral fascia to subdermal plane. The volume of fluid infiltrated ranged from $50-180 \mathrm{ml}$ per side.

Through an infraareolar $(2.5-3.5 \mathrm{~cm})$ skin incision, a nipple and areola skin flap of about $3 \mathrm{~mm}$ thickness was raised of the underlying glandular tissue by sharp dissection. This represented the skin and very thin film of underlying fibrous/ductal tissue that was preserved to maintain the skin vascularity. Beyond the areola, dissection continued in all directions on top of the glandular tissue to its boundaries mapped preoperatively and confirmed during this superficial dissection preserving a thin rim of fat beneath the skin. Now the whole gland is attached only to the underlying pectoral fascia and surrounding usually thin layer of subcutaneous fat. With proper skin flap retraction using appropriate size L retractors, the inferior edge of the gland was grasped with Allis forceps, pulled up, and dissected from underlying pectoral fascia using a long-insulated needle tip electrode. Dissection proceeds easily through the loose areolar plane between the gland and the underlying pectoral fascia in all directions. Tumescent injection ensured bloodless field, and vascular channels passing from the underlying pectoral muscles to the gland/skin were easily visualized and cauterized above the pectoral fascia. Great care was taken to avoid violation of this fascia and/or injury to underlying pectoral muscle, to avoid future static or dynamic depression secondary to excessive scaring / adhesions between the skin and underlying muscle.

Once deep gland dissection is complete, the gland was delivered out of the skin incision aided 
by proper skin retraction and dissection of its remaining medial, upper, and lateral peripheral connection to subcutaneous fat. A variable but always little rim of fat was excised with the glandular tissue for even contour as indicated in most cases. Now the hemostasis was carefully reinsured suing bipolar cautery. Chest shape was assessed both visually and by palpation.

In most of the cases, the breast enlargement was purely glandular without redundancy, with thin surrounding subcutaneous fat. In such cases, no further measure was needed apart from wound closure.

Liposuction using a $3 \mathrm{~mm}$ cannula through the same incision was done in cases with fatty element and/or thick subcutaneous fat peripheral to the excised gland. This ensured athletically pleasing chest wall contour and prevented saucer chest wall deformity. In the rare occasion of mild skin redundancy, the wide discontinuous undermining by liposuction allowed better skin redistribution.

The incision was closed by interrupted $5 / 0$ Polyprolen sutures. No drains were used.

\section{Post-operative instructions and follow-up:}

Office work and exercise not involving the pectoral muscles were allowed after one week. Activity that would involve the pectoral muscles or the shoulder was avoided for 4 weeks, during this period a compression garment was used.

Patients were seen on $2^{\text {nd }}$ post-operative day before the end of $1^{\text {st }}$ week and 10-12 days. The assessment included possible early complications including nipple and areola vascular compromise, hematoma, or seroma.

Patients were asked to report their satisfaction regarding their chest/breast contour at 6 months post-operative based on 1-10 scale grade where 10 represent the best results and 1 the worst results $(9-10=$ very satisfied, $7-8=$ satisfied, $5-6=$ neutral, 3-4=dissatisfied, and 1-2=very dissatisfied).

\section{RESULTS}

The series included 13 bodybuilder gynecomastia cases, aged between 23-41 years (mean 31.2 years). All cases suffered glandular tissue enlarge- ment that was managed by surgical excision through an infraareolar incision. In 4 cases a fatty element and/or relatively thick subcutaneous fat were managed by adjuvant liposuction after gland excision to obtain the desired contour and avoid saucer deformity. In those 4 cases, 3 reported a history of milder breast enlargement after puberty (idiopathic gynecomastia) aggravated recently with anabolic steroids use. The same periareolar incision was used for liposuction. Lipoaspirate volume ranged from $90-270 \mathrm{ml}$ (mean $167.5 \mathrm{ml}$ ). The weight of the individual excised gland ranged from 37-105 grams (mean 66 grams). Follow-up ranged from 10-63 months (mean 29.3 months). No cases of recurrence were reported during the follow-up period.

Early follow-up revealed mild hematoma on the $2^{\text {nd }}$ post-operative day in one case, this was managed conservatively till resolution after 2 weeks. No other early post-operative complications were reported. No cases of a nipple and/or areola vascular compromise. Periareolar wound yielded a fine unsightly scar in all cases, and scar hyperpigmentation blended well with the fading areolar color at the periphery of the areola.

All cases achieved aesthetically pleasing masculine chest contour at 6 months postoperative follow-up. A minor subareolar dynamic depression (depression with pectoral muscle contraction) was noticed on the right side of the first patient in this series at 6 months postoperative follow-up. This resolved spontaneously as observed at 2 years follow-up. Deserving mention, this depression was seen over the minor hematoma noticed in the early postoperative period.

Patients were either very satisfied (5 cases) or satisfied ( 8 cases) with their 6 months postoperative results (chest/pectoral muscle counter), rating their satisfaction in the range of 7-9 on a 110 scale (mean of 8). All cases gave a history of past and/or current anabolic steroids use. This was long-term use ranging from 9 months to 3 years of discontinuous use (used in cycles). Exact data regarding doses, specific active ingredients, or duration of use could not be accurately collected from patients. Cases were always taking different preparations over long periods and most of these were unregistered/illegal! medications. 

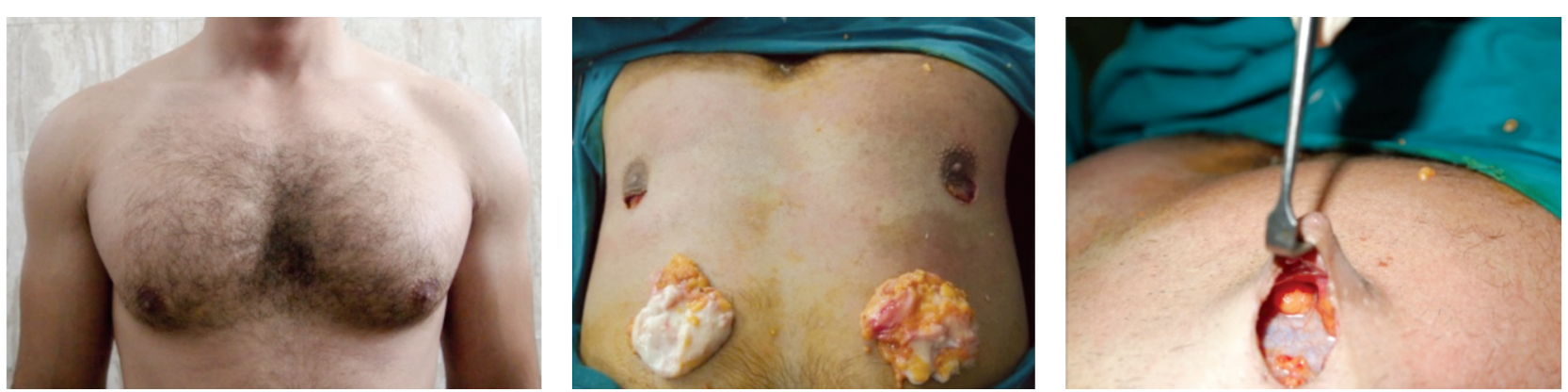

Fig. (1): Bodybuilder with moderate breast enlargement. (Left) Pre-operative standing view. (Middle) Intraoperative view of after glandular excision with a rim of surrounding fat to ensure smooth breast contour. $90 \mathrm{gm}$ and $98 \mathrm{gm}$ of tissue were excised from the right and left breast through a semicircular infraareolar incision. No adjuvant liposuction was used. (Right) Left side showing the gland bed with preserved pectoral fascia and a thin areolar skin flap.
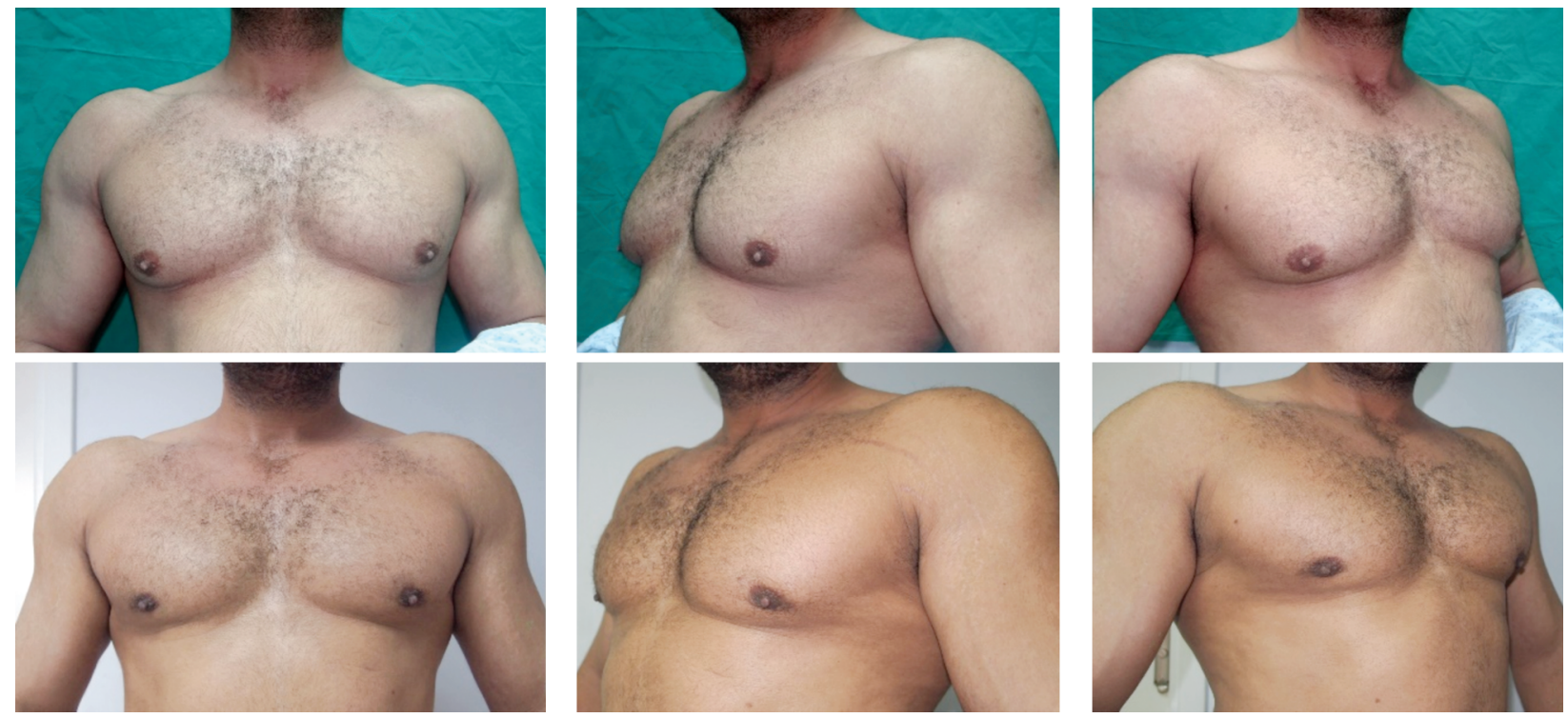

Fig. (2): (Above) Pre-operative views of a 37-year-old bodybuilder with moderate (grade IIa) gynecomastia. (Blow) 2 years post-operative. The glandular tissue together with a film of peri glandular fat was excised through a semicircular infraareolar incision. No liposuction was done.
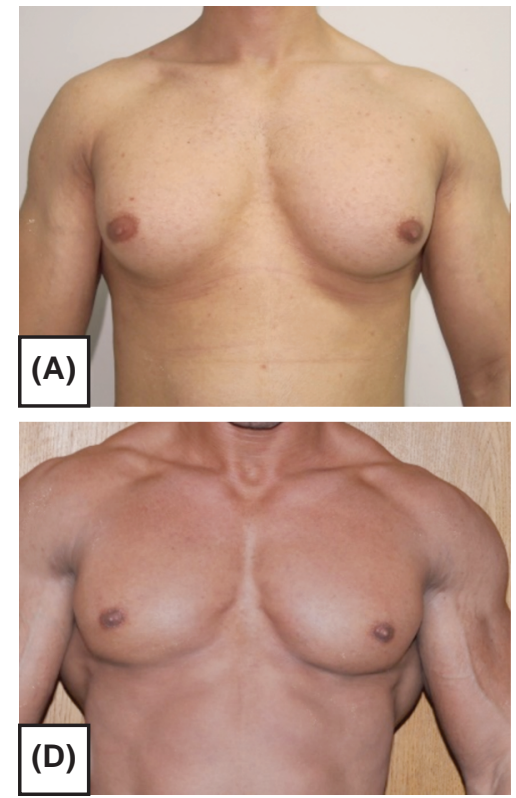
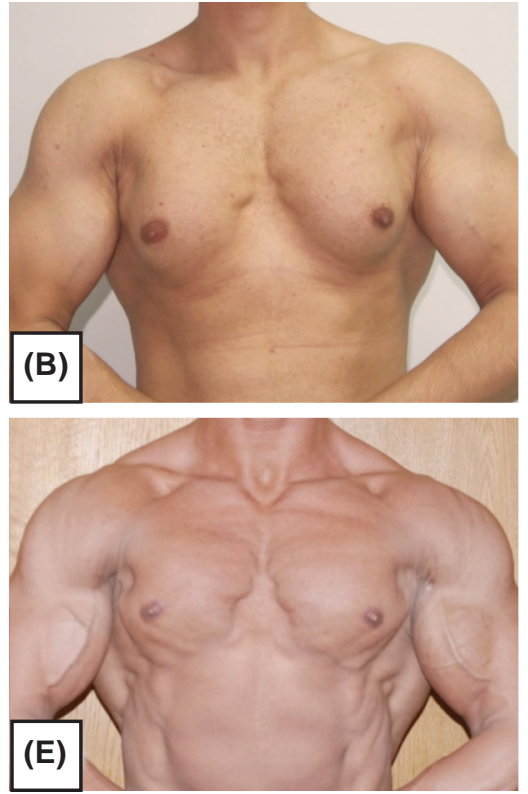


Fig. (3): 29 years old bodybuilder with moderate gynecomastia. The glandular tissue was excised through periareolar incision followed by adjuvant liposuction. (Above) Pre-operative. (Blow) 3 years post-operative. Comparing pre-and post-operative photos while the pectoral muscles maximally contracted (Photos B \& E) is a useful mean to accurately assess the results. Comparing the other photos at rest $(\mathrm{A} \& \mathrm{D} / \mathrm{C} \& \mathrm{~F})$ may be less impressive because of the increased pectoral muscle bulk in postoperative photos making overall chest volume comparable. Those rest photos are best judged by comparing the nearly conical preoperative breast shape (subareolar gland and fat) to the well-defined/unmasked hypertrophied pectoral muscles in post-operative photos. 
Table (1): Summary of patients' data and results.

\begin{tabular}{|c|c|c|c|c|c|c|c|c|}
\hline & Age & $\begin{array}{l}\text { Simon } \\
\text { Grade }\end{array}$ & $\begin{array}{l}\text { Adjuvant } \\
\text { liposuction }\end{array}$ & $\begin{array}{l}\text { Excised } \\
\text { tissue }\end{array}$ & Complications & Follow-up & $\begin{array}{c}\text { Patients' } \\
\text { satisfaction } \\
\text { grading on } \\
1-10 \text { scale }\end{array}$ & $\begin{array}{c}\text { Patient } \\
\text { satisfaction }\end{array}$ \\
\hline 1 & 37 & IIa & - & $105 / 97 \mathrm{gm}$ & Minor hematoma right side & 63 months & 8 & Satisfied \\
\hline 2 & 29 & IIa & $150 \mathrm{ml}$ & $83 / 70 \mathrm{gm}$ & & 37 months & 9 & Very Satisfied \\
\hline 3 & 27 & $*$ & $90 \mathrm{ml}$ & $45 / 37 \mathrm{gm}$ & & 48 months & 7 & Satisfied \\
\hline 4 & 39 & I & - & $51 / 45 \mathrm{gm}$ & & 25 months & 9 & Very Satisfied \\
\hline 5 & 26 & IIa & - & 90/98 gm & & 34 months & 7 & Satisfied \\
\hline 6 & 41 & I & - & $47 / 55 \mathrm{gm}$ & & 25 months & 9 & Very Satisfied \\
\hline 7 & 28 & IIa & $270 \mathrm{ml}$ & $67 / 80 \mathrm{gm}$ & & 47 months & 8 & Satisfied \\
\hline 8 & 35 & I & - & $45 / 50$ & & 19 months & 8 & Satisfied \\
\hline 9 & 33 & IIa & - & $74 / 90 \mathrm{gm}$ & & 21 months & 7 & Satisfied \\
\hline 10 & 32 & IIa & & $88 / 65 \mathrm{gm}$ & & 26 months & 9 & Very Satisfied \\
\hline 11 & 23 & I & - & $45 / 40 \mathrm{gm}$ & & 10 months & 9 & Very Satisfied \\
\hline 12 & 26 & IIa & 160 & $73 / 80$ & & 14 months & 7 & Satisfied \\
\hline 13 & 30 & I & - & $43 / 52 \mathrm{gm}$ & & 12 months & 8 & Satisfied \\
\hline
\end{tabular}

* Mild glandular enlargement with nipple/skin redundancy.

\section{DISCUSSION}

Bodybuilder gynecomastia is always secondary to the use/abuse of anabolic steroids and/or overthe-counter prohormones and supplements, presenting mainly by glandular tissue enlargement with little fatty deposits in some cases. Almost complete gland excision is the mainstay of management to avoid recurrence. Incomplete excision with retention of hormone-sensitive glandular tissue carries a high risk of recurrence especially with continued use of anabolic steroids [13]. Owing to professional competition and awareness of their physique, bodybuilder seeks perfect body shape. This is a real challenge in their gynecomastia management.

In the current study, 13 cases of bodybuilder gynecomastia were surgically corrected using glandular excision alone in 9 cases and glandular excision followed by limited volume liposuction in 4 cases. Cases were suffering from mild to moderate breast enlargement without redundant skin (Simon grade I \& IIa). All cases reported long-term past and/or current use of anabolic steroids.

In all cases, an infraareolar incision was used for the surgical excision of the glandular tissue, and the adjuvant liposuction needed in some cases. All incision was unsightly at 6 months postoperative. Hyperpigmentation is a common drawback in scars of colored races, and cases in this study were not an exception. Scar pigmentation was seen in all cases, but this blended nicely with gradual lighting of the areolar brown color at the areolar border. The tensionless wound closure of pre-expanded skin by glandular enlargement probably contributed to the fine scaring observed.

In this series, to ensure an almost complete surgical excision of glandular tissue, a thin (about $3 \mathrm{~mm}$ thick) areola and nipple skin flap was sharply raised from the inferior periareolar skin incision. This ensured the skin vascularity while keeping almost the whole gland beneath to be excised. In the current study, no cases of nipple/areola vascular compromise were reported. The relatively thin nipple/areolae skin allowed better shrinkage of areolar size during subsequent healing over the early postoperative months, another advantage of this thin flap.

Post-operative adhesion between the nipple/areolar skin and underlying pectoral muscle is a potential drawback of such excessive thinning, with little buffering tissue in-between. Such adhesions which become only apparent/become accentuated with pectoral muscle contraction are not accepted by bodybuilder with a high level of professional competition. Preserving pectoral fascia integrity is cardinal for the prevention of such adhesions, also adequately securing the hemostasis without excessive tissue fulguration is an important preventive measure [12]. Hematoma collection or even excessive tissue fulguration by wide heavy coagulation would cause post-operative adhesions with the resultant often dynamic contour irregularity. In all cases of the current study, the pectoral fascia was carefully preserved. Dissection of the glandular tissue on top of this fascia was carried out with the gentleness of perforator flap dissection using fine tip Colorado needle dissection and 
precise bipolar cauterization under vision with proper skin and tissue retraction. The clear bloodless field provided by the initial tumescent fluid injection was of great help in such dissection.

The increased vascularity is an unmodifiable bleeding risk factor and post-operative hematoma in bodybuilders [12-14]. Other modifiable hematoma risk factors were manipulated to reduce bleeding/ hematoma risk to a minimum. Any blood-thinning medications or supplements (anabolic steroids, omega 3 fatty acids, aspirin, and high doses of Vit. E) were stopped at least 2 weeks pre-operative. Pectoral muscle rest with gentle compression garments for 4 weeks was a regular postoperative regimen. Only in one case in this study, a minor hematoma was observed.

Almost complete glandular tissue excision keeping only thin skin flap would results in saucer deformity in non-bodybuilder gynecomastia. In bodybuilder gynecomastia with mainly glandular enlargement and thin subcutaneous fat in most of the cases, complete gland excision alone would be adequate to achieve natural chest contour [12]. Adjuvant liposuction would be needed in cases with fatty elements and/or relatively thicker subcutaneous pectoral fat. In the current series, just surgical excision of the enlarged gland was adequate to chive the desired chest contour in 9 out of 13 cases $(69.2 \%)$ of cases. In 4 cases $(30.2 \%)$ with fatty elements/thick subcutaneous pectoral fat, adjuvant small volume liposuction was used to achieve the desired contour. Lipoaspirate volume from both sides ranged between $90 \mathrm{ml}$ to $270 \mathrm{ml}$ (mean $167.5 \mathrm{ml}$ ). A small $3 \mathrm{~mm}$ diameter Mercedes tip liposuction cannula was used in all cases, to ensure smooth contour. The same periareolar incision was used for liposuction. Apart from better contouring, liposuction also provided discontinuous skin undermining for better skin redistribution. This was very important in one case with visible nipple/skin redundancy, in which the smallest volume of lipoaspirate $(90 \mathrm{ml})$ was liposuctioned from a relatively almost the whole pectoral region using low negative pressure, the aim was to create a wide surface area for skin redistribution to improve the nipple/skin redundancy.

In the current study, only one case suffered from mild hematoma with later dynamic depression of the affected area. The latter resolved spontaneously during the $2^{\text {nd }}$ post-operative year. Cases were either very satisfied (5 cases) or satisfied ( 8 cases) with their results at 6 months post-operative and no cases of recurrence were reported in a mean of 29.3 months follow-up period. In a series of 38 cases of bodybuilder gynecomastia, using only direct surgical gland excision through periareolar incision Aiache [13] reported satisfactory results in all cases. Reported complications included hematoma in 4 cases. Follow-up period and recurrence rate were not reported. Babigian and Silverman [15] reported satisfactory results in a series of 20 bodybuilder gynecomastia cases obtained by a combination of direct excision and liposuction in all cases except two in whom only direct surgical excision was done. Reported complications in this series included 2 cases of hematoma and one case of bilateral seroma, managed by surgical evacuation and aspiration, respectively. Recurrence in 3 cases in this series was reported and was related to continued use of anabolic steroids in 2 of them. They reported a less aggressive gland excision leaving a button of (hormone-sensitive) tissue beneath the areola in most cases. More radical areolar skin thinning was preserved only to the leanest cases.

A zero-recurrence rate was reported by Blau and Hazani [12] in the largest series of 1073 bodybuilder gynecomastia published. They were adopting a radical gland excision with an areolar flap thickness of 2-3mm thickness only, to get rid of any hormone-sensitive tissue, as continued use of anabolic steroids is always anticipated. This approach of aggressive gland excision was adopted in the current small series and accounted for the absence of recurrence over a mean of 29.3 months follow-up period. No cases of areolar vascular compromise were reported by Blau and Hazani [12] or in this series, reflecting the safety of areolar flap thinning. Blau and Hazani [12] reported using adjuvant liposuction in $5 \%$ of cases.

Surgical excision of the glandular tissue is the main approach of bodybuilder gynecomastia correction with adjuvant liposuction variably reported [12-15]. In 4 cases of the current series (30.2\%), adjuvant small volume liposuction was used to achieve the desired breast contour. Three of them reported a history of milder breast enlargement after puberty which becomes more manifest after engagement in their sport and anabolic intake. The variable reporting of liposuction in bodybuilder gynecomastia correction [12-15] probably reflects a relative heterogenicity of studied groups between armature bodybuilder to the leanest professional athletes with very low body fat. In the current series, the later professional-level athletes with very low body fat required only direct gland excision to achieve the desired masculine look. Also, anabolic steroids induced glandular tissue hypertrophy on top of milder past idiopathic (fatty) gynecomastia would be is a contributing factor. 


\section{Conclusion:}

Bodybuilder gynecomastia represents a unique gynecomastia variant. Cases present with glandular tissue enlargement secondary to the use of anabolic steroids with a little fatty element if any. Management entails almost complete gland excision with adjuvant liposuction in some cases with a fatty element. Preservation of pectoral fascia and meticulous hemostasis is essential to avoid post-operative adhesions and contour irregularities in such demanding cases seeking a perfect look.

\section{REFERENCES}

1- Rahmani S., Turton P., Shaaban A. and Dall B.: Overview of gynecomastia in the modern era and the Leeds Gynaecomastia Investigation algorithm. Breast J., 17: 246-255, 2011.

2- Schonfeld W.A.: Gynecomastia in adolescence: Effect on body image and personality adaptation. Psychosom. Med., 24: 379-389, 1962.

3- Fagerlund A., Lewin R., Rufolo G., et al.: Gynecomastia: A systematic review. J. Plast. Surg. Hand Surg., 49: 311$318,2015$.

4- Ratnam B.V.: A new classification and treatment protocol for gynecomastia. Aesthet. Surg. J., 29: 26-31, 2009.

5- Lewis C.M.: Lipoplasty: treatment for gynaecomastia. Aesthetic Plast. Surg., 9: 287-292, 1985.

6- Morselli P.G. and Morellini A.: Breast reshaping in gynecomastia by the "pull-through technique": Considerations after 15 years. Eur. J. Plast. Surg., 35 (5): 365-371, 2012.
7- Lista F. and Ahmad J.: Power-assisted liposuction and the pull through technique for the treatment of gynecomastia. Plast. Reconst. Surg., 121 (3): 740-7, 2008.

8- Hammond D.C., Arnold J.F., Simon A.M. et al.: Combined use of ultrasonic liposuction with the pull-through technique for the treatment of gynecomastia. Plast. Reconst. Surg., 112 (3): 891-5, 2003.

9- Kim D.H., Byun I.H., Lee W.J., et al.: Surgical management of gynecomastia: subcutaneous mastectomy and liposuction. Aesthet. Plast. Surg., 40: 877-884, 2016.

10- Bowman J.D., Kim H. and Bustamante J.J.: Drug-induced gynecomastia. Pharmacotherapy, 32: 1123-1140, 2012.

11- Pope H.G. and Katz D.L.: Psychiatric and medical effects of anabolic-androgenic steroid use: A controlled study of 160 athletes. Arch. Gen. Psychiatry, 51: 375-382, 1994.

12- Blau M. and Hazani R.: Correction of Gynecomastia in Body Builders and Patients with Good Physique Plast. Reconstr. Surg., 135: 1-9, 2015.

13- Aiache A.E.: Surgical treatment of gynecomastia in the bodybuilder. Plast. Reconstr. Surg., 83: 61-66, 1989.

14- Reyes R.J., Zicchi S., Hamed H., et al.: Surgical correction of gynaecomastia in bodybuilders. Br. J. Clin. Pract., 49: 177-179, 1995.

15- Babigian A. and Silverman R.T.: Management of gynecomastia due to use of anabolic steroids in bodybuilders. Plast. Reconstr. Surg.,107: 240-242, 2001.

16- Simon B.E., Hoffman S. and Kahn S.: Classification, and surgical correction of gynecomastia. Plast. Reconstr. Surg., 51: 48-52, 1973. 